\title{
Suppression of p75NTR Does Not Promote Regeneration of Injured Spinal Cord in Mice
}

\author{
Xing-Yun Song, Jin-hua Zhong, Xin Wang, and Xin-Fu Zhou \\ Department of Human Physiology and Centre for Neuroscience, Flinders University, Adelaide 5001, Australia
}

The neurotrophin receptor p75NTR is the coreceptor for Nogo receptor, mediating growth cone collapse in vitro by MAG, myelin oligodendrocyte glycoprotein (Omgp), and Nogo. Whether p75NTR plays any role in the failure of nerve regeneration in vivo is not known. Immunohistochemical data showed that p75NTR was expressed in only a very small subset of ascending sensory axons but not in any corticospinal axons in the dorsal column of either normal or injured spinal cord. Using p75NTR-deficient mice, we showed that the depletion of the functional p75NTR did not promote the regeneration of the descending corticospinal tract and ascending sensory neurons in the spinal cord 2 weeks after spinal cord injury. Local administration of p75NTR-Fc fusion molecule, the dominant-negative receptor to block the function of neurite outgrowth inhibitors, did not improve regeneration of ascending sensory neurons in the injured spinal cord. Our results suggest that p75NTR may not be a critical molecule mediating the function of myelin-associated inhibitory factors in vivo.

Key words: axon; injury; regeneration; corticospinal tract; p75NTR; spinal cord

\section{Introduction}

Axons of peripheral nerves can regenerate spontaneously, but axons in the brain and spinal cord fail to regenerate in adult mammals after injury. Myelin-associated inhibitors are believed to play an important role in the failure of axonal regeneration in the CNS (Spencer et al., 2003; Zheng et al., 2003). Regeneration can be achieved in the mouse after spinal cord injury by injection of vaccine made from CNS myelin (Huang et al., 1999) and by inhibitor neutralizing antibodies (Caroni and Schwab, 1988). Three myelin-associated growth inhibitory proteins [MAG, myelin oligodendrocyte glycoprotein (Omgp), and Nogo] can bind to Nogo receptors (NgR). The existence of a coreceptor was predicted because NgR lacks transmembrane and intracellular domains (Woolf and Bloechlinger, 2002). The neurotrophin receptor p75NTR was shown to be the coreceptor of $\mathrm{NgR}$, and the NgR-p $75^{\text {NTR }}$ complex mediates growth cone collapse by all three myelin inhibitory factors in vitro (Wang et al., 2002). Biochemical evidence indicates that p75NTR interacts directly with GDP dissociation inhibitor, releasing activated RhoA, the critical signal for growth cone collapse (Yamashita and Tohyama, 2003). Thus, p75NTR seems to act as the convergent point for inhibitory factors to suppress the growth of regenerating axons. In addition,

Received Sept. 20, 2003; revised Nov. 14, 2003; accepted Nov. 17, 2003.

This work was supported by National Health and Medical Research Council (Australia) Grant 160052. X-Y.S. is supported by a scholarship from International Postgraduate Research Scholarship and Flinders University Research Scholarship. We thank Professor Moses Chao of New York University for the gift of rabbit polyclonal antibodies to p75NTR. We thank Drs. Shahram Barati and Steve Johnson for critical reading and valuable comments on this manuscript.

Correspondence should be addressed to Dr. Xin-Fu Zhou, Department of Human Physiology and Centre for Neuroscience, Flinders University, Adelaide 5001, Australia. E-mail: xin-fu.zhou@flinders.edu.au.

X. Wang's present address: Department of Biochemistry, Peking Union Medical College, Beijing, People's Republic of China.

DOI:10.1523/JNEUROSCI.4281-03.2004

Copyright $\odot 2004$ Society for Neuroscience $\quad 0270-6474 / 04 / 240542-05 \$ 15.00 / 0$ the regeneration of motor neurons was enhanced in p75NTR ${ }^{-1-}$ mice after peripheral nerve injury (Boyd and Gordon, 2001). However, the functional role of p75NTR in regeneration of the CNS in vivo has not been established. This is a very important issue requiring additional investigation because p75NTR has multiple functions (for review, see Dechant and Barde, 2002). In the present study, we hypothesized that the depletion of p75NTR may eliminate the inhibitory impact from myelin-associated inhibitory proteins and enhance the regeneration of the mammalian CNS after injury. We tested this hypothesis in p75NTR knock-out mice, and, surprisingly, the deletion of the p75NTR gene did not enhance neuroregeneration after spinal cord injury. Our results suggest that p75NTR may not be the sole molecule mediating the function of myelin-associated inhibitory factors in vivo.

\section{Materials and Methods}

Spinal cord injury. Animal experiments were performed under the guidelines of the National Health and Medical Research Council of Australia and approved by the Animal Welfare Committee of Flinders University. p75NTR knock-out mice $(n=24), 8-10$ weeks old, and age-matched wild-type BALB/c and $129 \mathrm{sv}$ mice $(n=24)$ were anesthetized with a mixture of $2 \%$ halothane in $\mathrm{O}_{2}$. To reduce surgical trauma and mortality, spinal cord injury in some animals was performed without laminectomy. To achieve this, soft tissue between the spine process of T8 and T9 was carefully removed with a pair of fine scissors. After removal of the periosteum and dura mater, the distance between the two vertebrae was $\sim 1$ $\mathrm{mm}$. Dorsal spinal cord injury was produced by either a crush with fine forceps, as described by Bradbury et al. (1999), or by transection of the dorsal column with a pair of fine iris scissors as described (Huang et al., 1999). The depth of the lesion, which was $\sim 1 \mathrm{~mm}$, was estimated by a mark placed on the tip of the iris scissors. Both methods generated a reproducible dorsal column lesion in mice as confirmed by anterograde tracing dyes. This improvement of the surgery significantly improved the general condition and increased the survival rate of animals. 
Expression of p75NTR in normal and injured spinal cord. To examine the expression of p75NTR in the spinal cord after injury, mice (BALB/c, $n=3$ ) were subject to spinal cord injury as described above, and two mice were used as uninjured control. Three days after spinal cord injury, sagittal and cross sections $(40 \mu \mathrm{m})$ were stained for $\mathrm{p} 75 \mathrm{NTR}$ with a rabbit polyclonal antibody to recombinant mouse p75NTR (a gift from Prof. Moses Chao, New York University, New York, NY), as described previously (Zhou et al., 1996).

Assessment of axonal regeneration. For labeling corticospinal tract (CST) in p75NTR knock-out mice $(n=8)$ and wild-type mice (BALB/c, $n=4 ; 129 \mathrm{sv}, n=4$ ), biotin-conjugated dextran amine (BDA) [molecular weight (MW), 10,000; Molecular Probes, Eugene, OR] solution $(0.2 \mu \mathrm{l}$, $10 \%$ ) was injected bilaterally into six points of the sensorimotor cortex at the depth of $0.5 \mathrm{~mm}$ from the brain surface using a micropipette. Two weeks after operation, animals were perfused intracardially with $4 \%$ paraformaldehyde, and spinal cords were postfixed in the same solution for $2 \mathrm{hr}$ at room temperature and then cryoprotected in 30\% sucrose overnight at $4^{\circ} \mathrm{C}$. Transverse sections of the spinal cords were cut at 50 $\mu \mathrm{m}$ thick on a cryostat $5 \mathrm{~mm}$ rostral and caudal to the lesion site. Consecutive sections were collected on slides directly. Several transverse sections at the T1 level were collected as well. Sections were incubated in Cy3-streptavidin for $2 \mathrm{hr}$ for fluorescence microscopy. A well-stained transverse section of T1 was used to count the total number of labeled CST axons. The numbers of CST axons on every 10th section from the lesion site were counted. The axon index was calculated as the ratio of the number of axons in each site to the number of axons at the level of T1.

For assessment of regeneration of sensory neurons in p75NTR knockout mice $(n=8)$ and wild-type mice (BALB/c, $n=4 ; 129$ sv, $n=4)$, ascending sensory axons were labeled with Fluoro-Ruby (FR) (dextran and tetramethylrhodamine; MW, 10,000; D-1817; Molecular Probes). One week after spinal cord injury, $0.2 \mu \mathrm{l}$ of $10 \% \mathrm{FR}$ was injected into the dorsal column $\sim 5 \mathrm{~mm}$ caudal to the lesion site using a micropipette. One week later, animals were perfusion fixed with $4 \%$ paraformaldehyde and sectioned in $40 \mu \mathrm{m}$ longitudinally. The sections were mounted directly onto slides for examination with a fluorescence microscope. FR-labeled axons in every third section were counted at various points at intervals of $500 \mu \mathrm{m}$, starting from the lesion site. The axon index was calculated as the ratio of the number of FR-labeled axons counted from each point in the dorsal column to the number of axons labeled in the dorsal column 3 $\mathrm{mm}$ caudal to the lesion site (mean \pm SEM).

In an additional set of experiments, soluble p75NTR-Fc protein, a fusion protein comprising the extracellular domain of p75NTR and Fc fragment of human IgG (R \& D Systems, Minneapolis, MN), or normal human $\operatorname{IgG}$ was administered after spinal cord injury (p75NTR-Fc: $\mathrm{BALB} / \mathrm{c}, n=4 ; 129 \mathrm{sv}, n=4$; IgG: $129 \mathrm{sv}, n=4 ; \mathrm{BALB} / \mathrm{c}, n=4)$. Gelfoam soaked with $10 \mu \mathrm{l}$ of p75NTR-Fc protein $(1 \mathrm{mg} / \mathrm{ml})$ or normal human $\operatorname{IgG}(1 \mathrm{mg} / \mathrm{ml})$ was applied to the lesion site, and the mice were allowed to survive for an additional $14 \mathrm{~d}$. The molecules delivered by this method could efficiently penetrate the spinal cord, as demonstrated by immunohistochemistry of human IgG (data not shown). Two days before the mice were killed, $0.2 \mu \mathrm{l}$ of cholera toxin B conjugated to HRP (CTBHRP) (1\%; List Biological Laboratories, Campbell, CA) solution was injected in each sciatic nerve. The tracer in the sagittal sections $(40 \mu \mathrm{m})$ of the spinal cord was visualized with the TMB (Sigma, St. Louis, MO) method, as described previously (Mesulam, 1978). TMB-stained axons were counted at various points with the interval of $500 \mu \mathrm{m}$ starting from the lesion site. The axon index was calculated as the ratio of the number of CTB-HRP-labeled axons counted from each point of the dorsal column to the number of axons labeled in the dorsal column $5 \mathrm{~mm}$ caudal to lesion site (mean \pm SEM).

Statistics. All statistical analyses in this study were performed with the two-tailed $t$ test.

\section{Results}

General conditions of all animals were observed daily in an open field after operation. Motor and bladder functions usually recovered within the first week, and no obvious difference in these
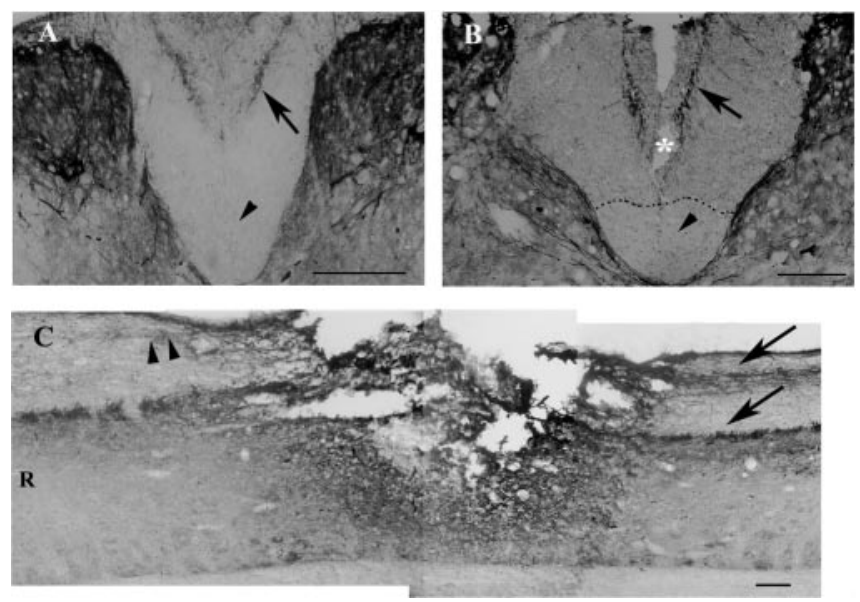

Figure 1. Localization of p75NTR in the normal and injured spinal cord. $A$, Cross-section of normal spinal cord. The arrow indicates p75NTR immunoreactivity in the dorsal column, and the arrowhead indicates the absence of p75NTR immunoreactivity in the CST. B, Cross-section $1 \mathrm{~mm}$ caudal to the lesion site $3 \mathrm{~d}$ after injury. The arrow indicates p75NTR immunoreactivity in the dorsal column, the arrowhead indicates the absence of p75NTR stain in the CST, and the asterisk indicates a cavity caused by injury. C, Sagittal spinal cord section $3 \mathrm{~d}$ after injury. The arrowhead indicates p75NTR immunoreactivity in the lesion site, and the double arrowheads indicate reduction in p75NTR immunoreactivity rostral to the lesion site. R, Rostral. Scale bars, $100 \mu \mathrm{m}$.

functions was observed between p75NTR mutant and control animals.

\section{Expression of p75NTR in normal and injured spinal cord}

In the spinal cord of normal mouse, p75NTR immunoreactivity was seen clearly in the dorsal horn and medial part of the dorsal column but not in the CST (Fig. 1A). Three days after spinal cord injury, p75NTR immunoreactivity was increased slightly in a very small subset of ascending sensory axons but not in any corticospinal axons in the dorsal column of either normal or injured spinal cord (Fig. $1 B$ ). In sagittal sections, p75NTR immunoreactivity was localized in the lesion site and reduced in the dorsal column rostral to the lesion site (Fig. 1C).

\section{Lack of enhanced regeneration in CST of p75NTR-deficient mice after spinal cord injury}

The macroscopic and microscopic appearances of injury sites were similar in mutant and wild-type mice $14 \mathrm{~d}$ after spinal cord injury. There was apparent scar formation in the lesion site. Scar tissue converged toward the dorsal surface of the spinal cord at the lesion site. Cy3-stained BDA-labeled axons were seen clearly in the CST in the dorsal funiculus in T1 cross-sections (Fig. 2). The number of CST axons in the T1 cross-sections of wild-type mice $(160 \pm 21)$ (Fig. $2 A)$ and of mutant mice (165 \pm 24$)$ (Fig. $2 B$ ) were similar. In most animals, the transection wound of the spinal cord is beyond the central canal; thus, the minor dorsolateral corticospinal axons were also severed. BDA-labeled axons were not found in the lesion site or in the spinal cord caudal to the lesion site in either group of mice (Fig. $2 C, D$ ). The number of axons decreased gradually from rostral to the lesion site. There was no significant difference in the axon index between mutant mice and wild-type mice at any level examined (Fig. 2E). No colateral sprouting fiber was found in either group of mice.

Lack of enhanced regeneration in sensory ascending axons of p75NTR-deficient mice after spinal cord injury

In both mutant (Fig. 3A) and wild-type (Fig. 3B) mice, FRlabeled axons were in their normal location of the dorsal column 

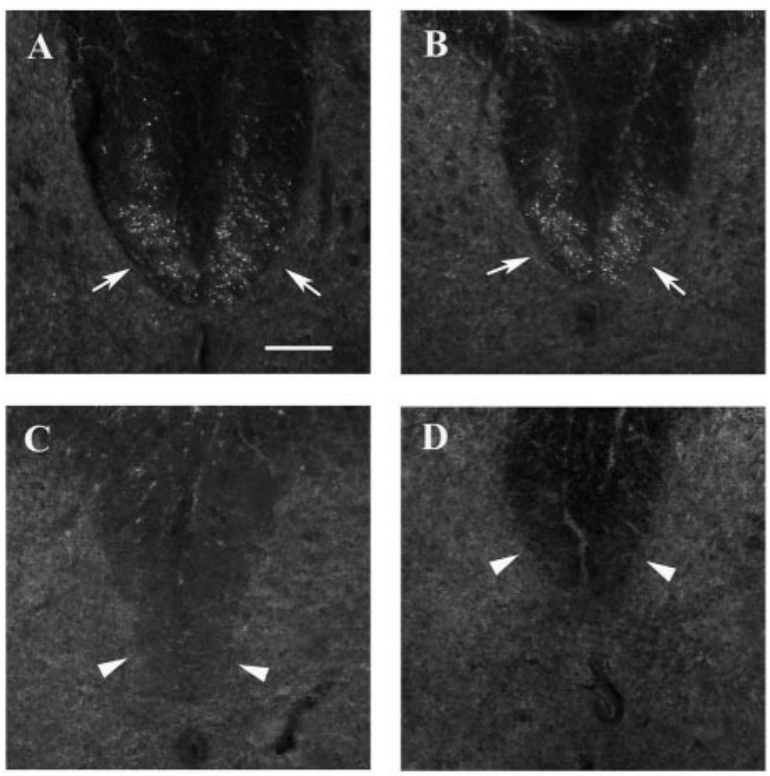

$\mathbf{E}$

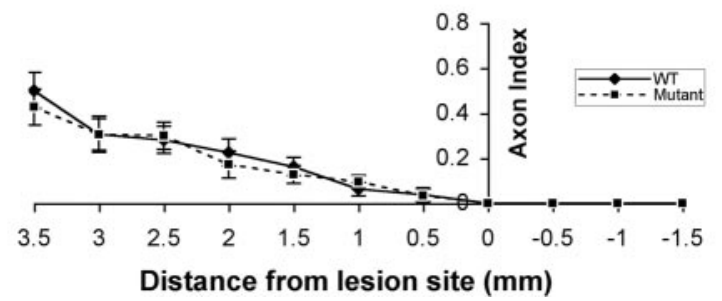

Figure 2. Anterograde labeling of corticospinal fibers in the injured spinal cord of p75NTR ${ }^{-1-}$ and control mice. A, B, T1 cross-sections of spinal cord from control mice and p75NTR ${ }^{-1-}$ mice, respectively. $C, D$, Cross-sections of spinal cord $0.5 \mathrm{~mm}$ caudal to the lesion site from control mice and p75NTR ${ }^{-1-}$ mice, respectively. Numerous corticospinal axons were labeled in the rostral segment (T1), but no axons were detected in the caudal sections. $E$, Quantification of the axon regeneration in wild-type controls and p75NTR ${ }^{-1-}$ mice. No statistically significant difference in axon index at any location was found between mutant mice and control animals. Scale bar, $100 \mu \mathrm{m}$. The arrows show BDA-labeled CST axons in their normal position. Arrowheads show the absence of BDA-labeled CST axons.

in sagittal sections. Presumed fibroblastic scar tissue was seen clearly in the lesion site (Fig. 3, arrows). FR-labeled axons stopped before the lesion site in both groups (Fig. 3, arrowheads). Axon terminals either formed dense core bulbs or arborized. In both groups of animals, some axons were observed growing into gray matter around the lesion site or toward the dorsal surface. No axons were found growing beyond the lesion site into the spinal cord rostral to the lesion site. In some sections, FR-labeled fibers aggregated in the dorsal column proximal to the lesion site in both groups. FR-labeled axons were counted in every third section at different levels along the dorsal column. The mean number of FR-labeled axons $3 \mathrm{~mm}$ caudal to the lesion site in mutant $(36 \pm 5)$ and in wild-type $(40 \pm 6)$ mice did not differ significantly $(p>0.05)$ (Fig. 3C).

\section{Lack of enhanced regeneration of ascending dorsal column} fibers after spinal cord injury in p75NTR-Fc-treated mice Fourteen days after delivery of p75NTR-Fc fusion protein into the lesioned spinal cord, the CTB-HRP-labeled fibers in the dorsal column failed to grow beyond the lesion site (Fig. 4A). A similar distribution pattern of CTB-HRP-labeled fibers was seen in the human IgG-treated group (Fig. 4B). CTB-HRP-labeled axonal bundles stopped abruptly before the lesion site with the growing tendency toward the dorsal surface at the lesion site. Axon terminal dense cores and axon arborization were found in both groups (Fig. 4C,D). CTB-HRP-labeled axons were counted in every third section at different levels running through the dorsal column. The mean number of axons labeled in the spinal cord $5 \mathrm{~mm}$ caudal to the lesion site in p75-Fc-treated mice was $66 \pm 10$ and in the human IgG-treated group was $68 \pm 11$. The axonal index shows no significant difference between the two groups at any level counted.

\section{Discussion}

The recent discovery that $\mathrm{p} 75 \mathrm{NTR}$ is a coreceptor for NgR, mediating effects of myelin-associated inhibitors on the neurite collapse, has triggered significant optimism in relation to regeneration of the CNS, because p75NTR can be a potential converging target to promote the regeneration. However, whether p75NTR contributes to the nerve regeneration in vivo is not known. In the present study, we propose that the depletion of p75NTR may promote regeneration in the CNS by blocking the Nogo-NgR pathway. To our surprise, we did not find any enhanced regeneration of CST after spinal cord lesion in p75NTR knock-out mice. We reasoned that the ineffectiveness of regeneration in p75NTR knock-out mice may be attributable to the lack of normal expression of p75NTR in corticospinal neurons (Giehl et al., 2001) (Fig. 1 ). To further test our hypothesis, we have examined the regeneration of ascending sensory neurons in the dorsal column after transection in the knock-out mice, because these neurons normally express p75NTR (Fig. 1), which may participate in the signal transduction of the Nogo-NgR system after nerve injury. Consistent with the result from the CST, the gene knock-out of p75NTR did not promote the regeneration of ascending sensory neurons in the dorsal column either. Our results suggest that p75NTR may not be a converging molecule mediating inhibitory functions of myelin inhibitory factors in vivo. Other receptors may mediate inhibitory functions of myelin-associated inhibitors on neurite growth in vivo after injury.

We used mutant mice in which a short form of the intracellular domain of p75NTR is preserved. The lack of effects of p75NTR knock-out on nerve regeneration in our model is unlikely attributable to the partial gene deletion in this mouse, because Wang et al. (2002) showed that the extracellular domain of p75NTR is required for the signal transduction of the Nogo-NgR pathway in vitro (Wang et al., 2002; Wong et al., 2002). Because p75NTR is the only member in the receptor family mediating functions of all neurotrophins, it is unlikely that a compensatory (redundancy) mechanism operates after the gene deletion, as we see in the epidermal growth factor family (Xian et al., 2001). To further reduce the possibility of a redundancy mechanism occurring in p75NTR knock-out mice, we examined the effects of the p75NTR extracellular domain Fc fusion molecule on the regeneration of ascending sensory neurons, because a previous study showed that this molecule suppressed functions of NgR ligands (Wang et al., 2002). However, when applied to the injured spinal cord, this fusion molecule did not promote the nerve regeneration of ascending sensory neurons in the spinal cord. Taken together, these findings suggest that, in vivo, p75NTR may not be a critical molecule controlling nerve regeneration in the CNS.

The differential actions of p75NTR on nerve regeneration in vivo and in vitro may be attributable to the complex multiple functions of $\mathrm{p} 75 \mathrm{NTR}$ in vivo. In addition to being a coreceptor for $\mathrm{NgR}, \mathrm{p} 75 \mathrm{NTR}$ is the common receptor for all neurotrophins. In combination with Trk (tropomyosin-related kinase) receptor ty- 

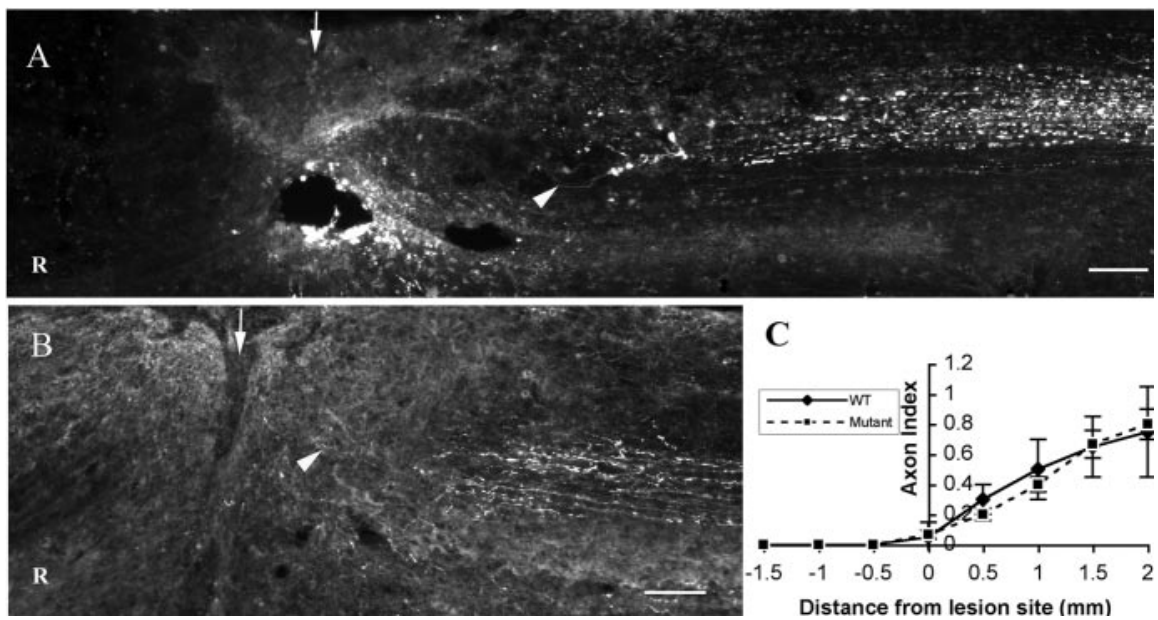

Figure 3. Anterograde labeling of dorsal column fibers in the injured spinal cord of $\mathrm{p} 75 \mathrm{NTR}^{-1-}$ and control mice. A, B, Sagittal sections of the injured spinal cord from p75NTR ${ }^{-1-}$ and control mice, respectively. FR-labeled axons stopped before the lesion site in both types of mice. C, Quantification of the dorsal column axons in wild-type controls and p75NTR ${ }^{-1-}$ mice. No statistically significant difference in the axon index at any location was found between mutant and control groups. The arrows show the lesion site, and arrowheads show axons stopped at the lesion site. Scale bars, $100 \mu \mathrm{m}$. R, Rostral to the lesion site.
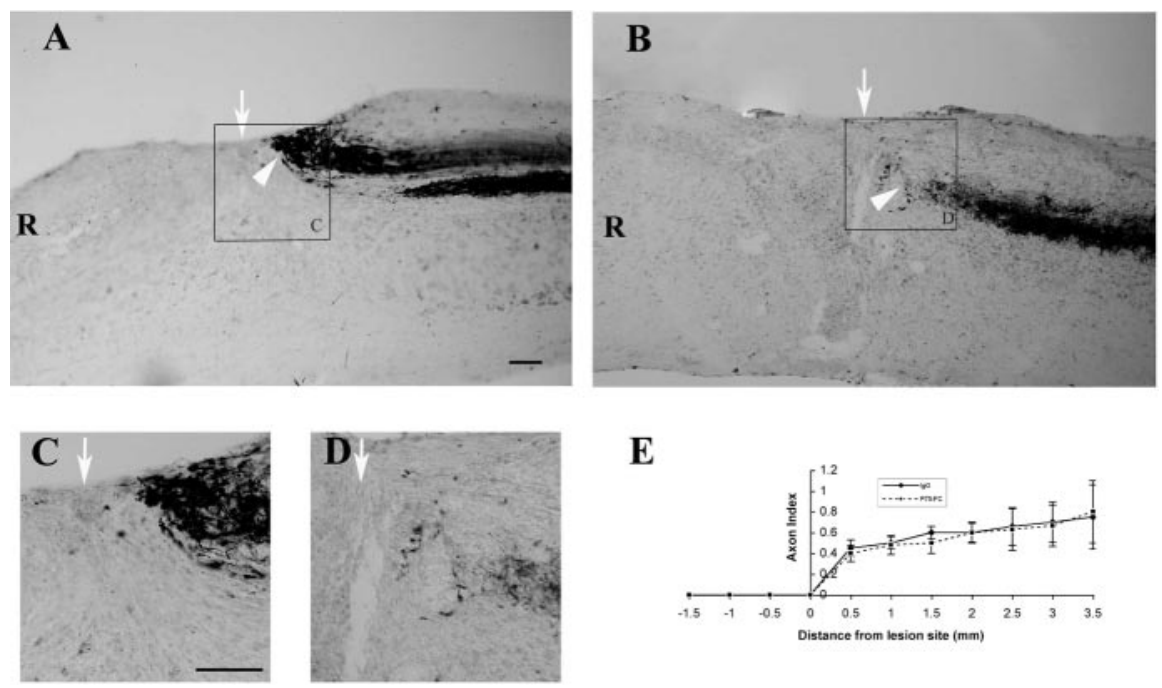

$\mathbf{E}$

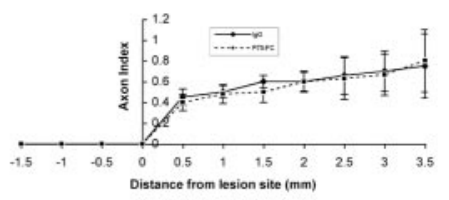

Figure 4. Anterograde labeling of dorsal column fibers in the injured spinal cord of mice treated with p75NTR-Fc or normal human IgG. $A, B$, Sagittal sections of the injured spinal cord from mice treated with p75NTR-Fc or normal human IgG, respectively. $C$, An enlarged view from the field in $A$ as marked by a square and an arrow. D, An enlarged view from the field in $B$ as marked by a square and an arrow. E, Quantification of the dorsal column axons in mice treated with p75NTR-Fc or normal human IgG. No statistically significant difference in the axon index at any location was found between the two groups of animals. The arrows show lesion site, and arrowheads show axons stopped abruptly. Scale bars, $100 \mu \mathrm{m}$ (the bar in $A$ also applies to $B$; the bar in Calso applies to $D)$. R, Rostral to the lesion site.

rosine kinases, p75NTR can mediate the signal transduction leading to enhanced neurite outgrowth in the presence of neurotrophins by enhancing the binding of neurotrophins to Trk receptors (Hempstead et al., 1991; Mahadeo et al., 1994; Chao and Hempstead, 1995). In the absence of trkA, p75NTR alone also mediates neurite outgrowth from embryonic rat hippocampal neurons and chick ciliary neurons stimulated by NGF (Brann et al., 1999; Yamashita et al., 1999). Binding of neurotrophins to p75NTR decreases Rho activity to induce neurite outgrowth (Yamashita et al., 1999). After spinal cord lesion, the gene expression of all neurotrophins is upregulated (Ebadi et al., 1997). Thus, p75NTR in vivo may mediate positive signals stimulated by neurotrophins as well as negative signals from Nogo, MAG, and Omgp via NgR pathways. It is known that sensory neurons primed by neurotrophins do not respond to the inhibitory signals stimulated by MAG (Cai et al., 1999). Other growth inhibitory factors, such as chondroitin sulfate proteoglycans, which do not signal via p75NTR, may play critical roles in the failure of CNS regeneration (Morgenstern et al., 2002). After nerve injury, ascending sensory neurons expressing p75NTR may be exposed to both neurotrophins and growth inhibitory factors sequentially or simultaneously. The function of p75NTR on neurite outgrowth may depend on the balance between positive and negative signals generated locally in the injured spinal cord. Breaking the balance by introducing exogenous neurotrophins or knock-out of growth inhibitors may promote nerve regeneration. Deletion of the NogoA gene (Kim et al., 2003; Simonen et al., 2003; Zheng et al., 2003) or neutralization of an epitope in a myelin-associated inhibitor by a monoclonal antibody (Caroni and Schwab, 1988) enhanced regeneration of the CST. In contrast, introduction of neurotrophins into the spinal cord significantly enhances regeneration of descending and ascending pathways after spinal cord injury (Schnell et al., 1994; Houweling et al., 1998; Oudega and Hagg, 1999; Ramer et al., 2000). However, direct evidence that p75NTR mediates these positive and negative signals leading to enhanced nerve regeneration or growth cone collapse after nerve injury in vivo is lacking.

One evidence that p75NTR may mediate neurite growth in vivo comes from the study in $75 \mathrm{NTR}^{-/-} \mathrm{NGF}^{+/+}$transgenic mice in which sympathetic neurons sprout and grow extensively in the white matter of the brain (Walsh et al., 1999), suggesting p75NTR may normally (without injury) suppress the neurite growth in vivo. In contrast, after nerve injury, when neurotrophins are upregulated and the myelin sheath is disrupted, p75NTR may promote neurite growth. After sciatic nerve injury, p75NTR is required for the basket formation of sympathetic sprouting around large sensory neurons (Ramer et al., 1999) and sympathetic sprouting fibers are associated with p75NTR-expressing satellite cells in the dorsal root ganglia (Zhou et al., 1999). Blocking any neurotrophin, including BDNF with neutralizing antibodies, can partially block the sympathetic sprouting (Deng et al., 2000a). Because sympathetic neurons do not express trkB, the action of BDNF on sympathetic sprouting is most likely via p75NTR (Deng et al., 2000b).

In conclusion, the depletion of p75NTR did not promote the regeneration of the descending CST and ascending sensory neurons in the spinal cord of p75NTR knock-out mice. Administration of a soluble p75NTR-Fc molecule in the injured spinal cord in mice did not promote regeneration of ascending sensory neurons either. Our results suggest that p75NTR is not required for 
the suppression of regeneration of CNS neurons in vivo, and additional efforts should be made to identify an alternate coreceptor(s) for Nogo receptor.

\section{References}

Boyd JG, Gordon T (2001) The neurotrophin receptors, trkB and p75, differentially regulate motor axonal regeneration. J Neurobiol 49:314-325.

Bradbury EJ, Khemani S, King VR, Priestley JV, McMahon SB (1999) NT-3 promotes growth of lesioned adult rat sensory axons ascending in the dorsal columns of the spinal cord. Eur J Neurosci 11:3873-3883.

Brann AB, Scott R, Neuberger Y, Abulafia D, Boldin S, Fainzilber M, Futerman AH (1999) Ceramide signaling downstream of the p75 neurotrophin receptor mediates the effects of nerve growth factor on outgrowth of cultured hippocampal neurons. J Neurosci 19:8199-8206.

Cai D, Shen Y, De Bellard M, Tang S, Filbin MT (1999) Prior exposure to neurotrophins blocks inhibition of axonal regeneration by MAG and myelin via a cAMP-dependent mechanism. Neuron 22:89-101.

Caroni P, Schwab ME (1988) Antibody against myelin-associated inhibitor of neurite growth neutralizes nonpermissive substrate properties of CNS white matter. Neuron 1:85-96.

Chao MV, Hempstead BL (1995) p75 and Trk: a two-receptor system. Trends Neurosci 18:321-326.

Dechant G, Barde YA (2002) The neurotrophin receptor p75(NTR): novel functions and implications for diseases of the nervous system. Nat Neurosci 5:1131-1136.

Deng YS, Zhong JH, Zhou XF (2000a) Effects of endogenous neurotrophins on sympathetic sprouting in the dorsal root ganglia and allodynia following spinal nerve injury. Exp Neurol 164:344-350.

Deng YS, Zhong JH, Zhou XF (2000b) BDNF is involved in sympathetic sprouting in the dorsal root ganglia following peripheral nerve injury in rats. Neurotoxicol Res 1:311-322.

Ebadi M, Bashir RM, Heidrick ML, Hamada FM, Refaey HE, Hamed A, Helal G, Baxi MD, Cerutis DR, Lassi NK (1997) Neurotrophins and their receptors in nerve injury and repair. Neurochem Int 30:347-374.

Giehl KM, Rohrig S, Bonatz H, Gutjahr M, Leiner B, Bartke I, Yan Q, Reichardt LF, Backus C, Welcher AA, Dethleffsen K, Mestres P, Meyer M (2001) Endogenous brain-derived neurotrophic factor and neurotrophin-3 antagonistically regulate survival of axotomized corticospinal neurons in vivo. J Neurosci 21:3492-3502.

Hempstead BL, Martin-Zanca D, Kaplan DR, Parada LF, Chao MV (1991) High-affinity NGF binding requires coexpression of the trk protooncogene and the low-affinity NGF receptor. Nature 350:678-683.

Houweling DA, Lankhorst AJ, Gispen WH, Bar PR, Joosten EA (1998) Collagen containing neurotrophin-3 (NT-3) attracts regrowing injured corticospinal axons in the adult rat spinal cord and promotes partial functional recovery. Exp Neurol 153:49-59.

Huang DW, McKerracher L, Braun PE, David S (1999) A therapeutic vaccine approach to stimulate axon regeneration in the adult mammalian spinal cord. Neuron 24:639-647.

Kim JE, Li S, GrandPre T, Qiu D, Strittmatter SM (2003) Axon regeneration in young adult mice lacking Nogo-A/B. Neuron 38:187-199.

Mahadeo D, Kaplan L, Chao MV, Hempstead BL (1994) High affinity nerve growth factor binding displays a faster rate of association than p140trk binding. Implications for multi-subunit polypeptide receptors. J Biol Chem 269:6884-6891.
Mesulam MM (1978) Tetramethyl benzidine for horseradish peroxidase neurohistochemistry: a non-carcinogenic blue reaction product with superior sensitivity for visualizing neural afferents and efferents. J Histochem Cytochem 26:106-117.

Morgenstern DA, Asher RA, Fawcett JW (2002) Chondroitin sulphate proteoglycans in the CNS injury response. Prog Brain Res 137:313-332.

Oudega M, Hagg T (1999) Neurotrophins promote regeneration of sensory axons in the adult rat spinal cord. Brain Res 818:431-438.

Ramer MS, Thompson SW, McMahon SB (1999) Causes and consequences of sympathetic basket formation in dorsal root ganglia. Pain Suppl 6:S111-120.

Ramer MS, Priestley JV, McMahon SB (2000) Functional regeneration of sensory axons into the adult spinal cord. Nature 403:312-316.

Schnell L, Schneider R, Kolbeck R, Barde YA, Schwab ME (1994) Neurotrophin-3 enhances sprouting of corticospinal tract during development and after adult spinal cord lesion. Nature 367:170-173.

Simonen M, Pedersen V, Weinmann O, Schnell L, Buss A, Ledermann B, Christ F, Sansig G, van der Putten H, Schwab ME (2003) Systemic deletion of the myelin-associated outgrowth inhibitor Nogo-A improves regenerative and plastic responses after spinal cord injury. Neuron 38:201-211.

Spencer T, Domeniconi M, Cao Z, Filbin MT (2003) New roles for old proteins in adult CNS axonal regeneration. Curr Opin Neurobiol 13:133-139.

Walsh GS, Krol KM, Crutcher KA, Kawaja MD (1999) Enhanced neurotrophin-induced axon growth in myelinated portions of the CNS in mice lacking the p75 neurotrophin receptor. J Neurosci 19:4155-4168.

Wang KC, Kim JA, Sivasankaran R, Segal R, He Z (2002) P75 interacts with the Nogo receptor as a co-receptor for Nogo, MAG and OMgp. Nature 420:74-78.

Wong ST, Henley JR, Kanning KC, Huang KH, Bothwell M, Poo MM (2002) A p75(NTR) and Nogo receptor complex mediates repulsive signaling by myelin-associated glycoprotein. Nat Neurosci 5:1302-1308.

Woolf CJ, Bloechlinger S (2002) Neuroscience. It takes more than two to Nogo. Science 297:1132-1134.

Xian CJ, Li L, Deng YS, Zhao SP, Zhou XF (2001) Lack of effects of transforming growth factor-alpha gene knockout on peripheral nerve regeneration may result from compensatory mechanisms. Exp Neurol 172:182-188.

Yamashita T, Tohyama M (2003) The p75 receptor acts as a displacement factor that releases Rho from Rho-GDI. Nat Neurosci 6:461-467.

Yamashita T, Tucker KL, Barde YA (1999) Neurotrophin binding to the p75 receptor modulates Rho activity and axonal outgrowth. Neuron 24:585-593.

Zheng B, Ho C, Li S, Keirstead H, Steward O, Tessier-Lavigne M (2003) Lack of enhanced spinal regeneration in Nogo-deficient mice. Neuron 38:213-224.

Zhou XF, Rush RA, McLachlan EM (1996) Differential expression of the p75 nerve growth factor receptor in glia and neurons of the rat dorsal root ganglia after peripheral nerve transection. J Neurosci 16:2901-2911.

Zhou XF, Deng YS, Chie E, Xue Q, Zhong JH, McLachlan EM, Rush RA, Xian CJ (1999) Satellite-cell-derived nerve growth factor and neurotrophin-3 are involved in noradrenergic sprouting in the dorsal root ganglia following peripheral nerve injury in the rat. Eur J Neurosci 11:1711-1722. 